\title{
Modern polyethylenes for wear and scaling applications
}

\author{
E Lakous Pipe and Buoy Pty Ltd, Australia
}

\begin{abstract}
This paper will seek to highlight the performance attributes of modern age polyethylenes, the use of which is being limited due to a lack of practical information in the marketplace, namely ambiguity over the definition of ultra-high molecular weight polyethylene (UHMWPE); lack of exposure to the performance characteristics of UHMWPE under real-life scenarios; and an incorrect perception of high pricing and lack of customisability.

This paper should condense not only the known UHMWPE information but also reflect it as a subset of piping applications specifically.

The UHMWPE family is traditionally thought of as the most impact and abrasion resistant of any PE, but it also has a technically unlimited number of grades (molecular weights) as defined by ISO 11542 (International Organization for Standardization 2001), which defines products only by their minimum melt flow index - an attribute not directly associable with abrasion or impact performance.

This paper will seek to distinguish specific mechanical data with reference to pipeline performance for specific grades, subsequently correlating and comparing against each other and the baseline PE product, high-density polyethylene (HDPE, PE100).

By directly comparing testing data and referencing site-specific performance, the author will endeavour to provide the first comprehensive article on this matter.
\end{abstract}

Keywords: scaling, wear, abrasion, slurry, ultra-high molecular weight polyethylene (UHMWPE)

\section{Introduction}

Ultra-high molecular weight polyethylene (UHMWPE) is a linear polyethylene resin. ISO 11542 (International Organization for Standardization 2001) covers the definition of UHMWPE by melt flow index, which in turn is a correlated by-product of molecular weight, where a specific accepted testing method can be found as ASTM D1601-12 (ASTM International 2012).

Generally speaking, any PE with a molecular weight of $>1.5 \times 10^{6} \mathrm{~g} / \mathrm{mol}$ is likely to be considered UHMWPE by way of melt flow index. However, this can be misleading, as pipe performance has nothing to do with melt flow index.

This attribute, and denomination, does not correct for price or performance, both of which will be considered in this paper, where focus will be placed on abrasive wear and scaling.

We will further reference the testing parameters against method of manufacture. Piping would be extruded, whereas much of the historical correlation data is based on moulded sheet - a product that has been commonplace for 50 years.

We will consider three main classes in our discussions:

- $1.5 \times 10^{6} \mathrm{~g} / \mathrm{mol}$.

- $3.5 \times 10^{6} \mathrm{~g} / \mathrm{mol}$.

- $8.2 \times 10^{6} \mathrm{~g} / \mathrm{mol}$.

An iteration of which is available from each of the big three global suppliers - Ticona, Braskem, and Mitsui. 
The variety of grades came about as a result of the competition of these major suppliers, and their distributors. Each wanting a specific blend and brand that they could patent and prohibit others from using. Common brands such as TIVAR, Polystone7000, Thordon, Vesconite, WearPro, EnergyPro, PE1000, Matrox, FQ7000 and many others are all commonly made from Ticona raw material. Testing in the results section will refer to these by country of origin and not directly, as the purpose of this paper is not to be derogatory to any specific brand.

By comparison, PE100 (the pelletised version of HDPE used for piping extrusion) is in the order of $2 \times 10^{5} \mathrm{~g} / \mathrm{mol}$. High-performance polyethylene (HPPE), which is gaining popularity, is a marginally higher molecular alternate than PE100, but still below the melt flow index of a UHMWPE.

Molecular weight in turn yields unique and heightened properties which could be of important benefit in optimising pipelines. The two that have the most bearing on pipeline tailings, paste and slurry applications are wear and scaling.

\subsection{Literature review of mechanical performance data correlating against impact and wear resistance}

UHMWPE has both the highest sliding abrasion resistance and highest notched impact strength of any commercial plastic.

The below diagram of volumetric wear loss (Figure 1) provides a good guideline as to what can be expected from $3.5 \times 10^{6} \mathrm{~g} / \mathrm{mol}$ UHMWPE as a baseline.

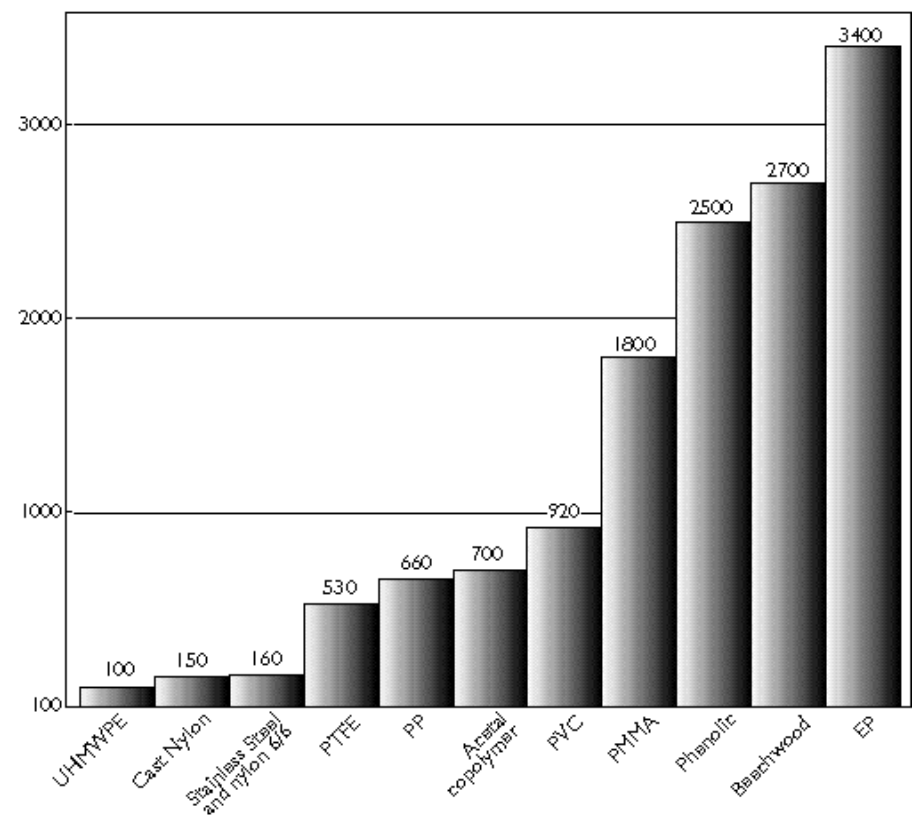

Figure 1 Drum abrasion testing of various commercial resins comparing volume loss as a proportion of baseline $100-$ UHMWPE $\left(3.5 \times 10^{6} \mathrm{~g} / \mathrm{mol}\right)$. Showing left to right: UHMWPE, nylon, stainless steel, Teflon (PTFE), Polypropylene (PP), acetal, Polyvinyl chloride, Perspex glass/similar (PMMA), Pinanolic, Beechwood, and ethylene-based rubber (EP) (Stein 1999)

As molecular weight increases from $3.5 \times 10^{6}$ to $8.2 \times 10^{6} \mathrm{~g} / \mathrm{mol}$, abrasion resistance is significantly improved (3:1 ratio) whilst impact strength is decreased from 120 to $100 \mathrm{~kJ} / \mathrm{m}^{2}$ (Stein 1999). For example, PA66 nylon lost 1.5 times the volume of UHMWPE under the same ASTM D256 conditions.

Figure 2 illustrates the notch impact performance. By comparison, PE100 notch impact ranges from 20 to $40 \mathrm{~kJ} / \mathrm{m}^{2}$. This is further confirmed through Ticona $\mathrm{GmbH}$ (2007). 


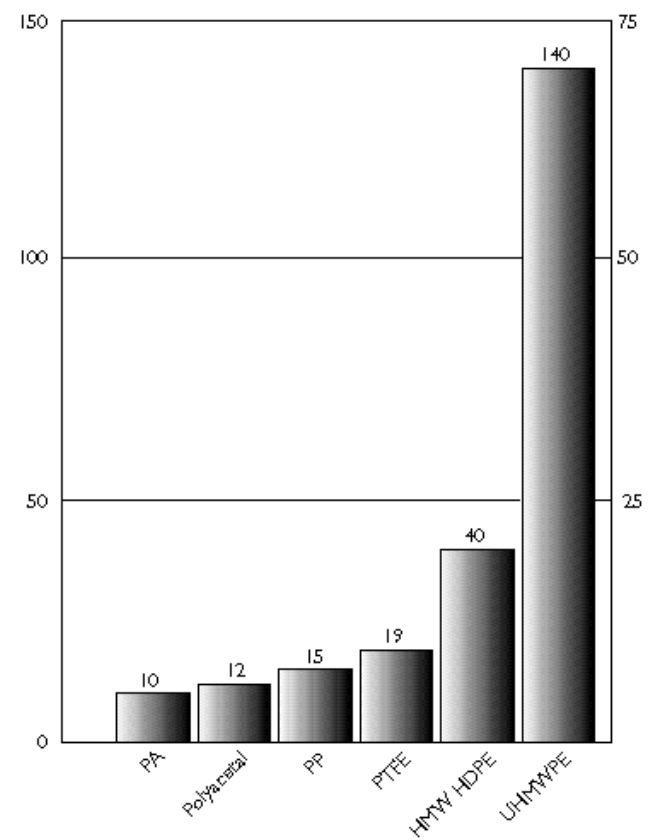

Figure 2 ASTM D256 izod notched impact test; $\mathrm{kJ} / \mathrm{m}^{2}$ comparison between UHMWPE and other materials. Showing left to right: PA, polyacetal, PP, PTFE, HPPE (HMW HDPE), and UHMWPE (taken from Braun \& Theyssen 1979)

In terms of pricing, it should be expected that $3.5 \times 10^{6} \mathrm{~g} / \mathrm{mol}$ UHMWPE would be approximately twice the cost of PE100 if not correcting for wear life (i.e. same internal diameter and wall thickness, but the pipe lasting longer).

Further, it should be expected that $8.2 \times 10^{6} \mathrm{~g} / \mathrm{mol}$ UHMWPE be almost three times the wear life of $3.5 \times 10^{6} \mathrm{~g} / \mathrm{mol}$, and approximately 1.5 times the price.

As Table 1 shows, if an application requires even longer life, such as in the case of abrasive copper slag as opposed to the less strenuous iron ore fines tailings, a higher grade can and should be chosen.

Table 1 Estimated performance based on literature review against molecular weight

\begin{tabular}{llll}
\hline Molecular weight (g/mol) & Abrasion & Impact & Price \\
\hline $10^{5}$ (PE100) & $1: 1$ & $1: 1$ & $1: 1$ \\
$1.5 \times 10^{6}$ & $3: 1$ & $2.5: 1$ & $1.5: 1$ \\
$3.5 \times 10^{6}$ & $6: 1$ & $3: 1$ & $2: 1$ \\
$8.2 \times 10^{6}$ & $10: 1$ & $2.5: 1$ & $3: 1$ \\
\hline
\end{tabular}

\subsection{Literature review of mechanical performance data correlating against surface roughness}

In addition to abrasion resistance, UHMWPE is extremely smooth, and is commonly used in pharmaceuticals for its NSF International and $3 A 3$ ratings. This can create benefits not only in scaling, but also in maximum dynamic head (particularly with slurries where suspension velocities are habitually designed at $>3.5 \mathrm{~m} / \mathrm{s}$ ).

The ISO 8295 (ISO 1995) co-efficient of friction for WearPro and EnergyPro is 0.05, as compared with $0.28-0.35$ for PE100 or 0.6 for steel. Surface roughness of $0.22 \mu \mathrm{m}$ is a leader in the pharmaceutical industry and can be used advantageously in mining applications. 


\subsection{Literature review summary}

In turn, a designer can:

- Capitalise on both 1.1 (abrasive performance) and 1.2 (lower surface roughness) simultaneously.

- Run a smaller wall thickness due to a reduction in maximum head and lower design pressure requirements (pending pumps).

- Run less power due to energy needs.

- Reduce wall thickness for wear life as a function of abrasive performance.

Thus, it is possible to design a pipeline to last longer, run leaner, and be of lower capital cost.

\section{$2 \quad$ Testing}

\subsection{Abrasion testing}

The author has endeavoured to offer testing results of various UHMWPE and PE100 grades, as noted in the introduction, extrusion and moulding results in a variation in abrasive performance (ASTM International 2011). Bearing this in mind, and the inability of most manufacturers to produce pipe (usually offering liners), the author has chosen to compare moulded sheet. Furthermore, to avoid any trademark issues, we have listed manufacturers by country of origin, rather than brand name.

This comparison was undertaken via an easily repeatable drum slurry wear test, iterations of which are usually referred to as a mortar wear index test (ASTM International 2015).

$2,800 \mathrm{rpm}$, diameter of solids $=0.5$ to $3 \mathrm{~mm}$ silica sand, $70 \%$ by weight.

Table 2 provides a vantage point for noting just how much wear performance variation can be seen within the world of UHMWPE.

As many of the alternate supplier materials are blends, we are not able to list the exact molecular weight in this table. However, noting our own listed brands and experience, it is quite clear that longer chains result in better performance.

Note the following:

- WearPro+ is a blend with a base of $8.2 \times 10^{6} \mathrm{~g} / \mathrm{mol}$.

- WearPro is a blend with a base of $4.5 \times 10^{6} \mathrm{~g} / \mathrm{mol}$.

- EnergyPro is a blend with a base of $2.5 \times 10^{6} \mathrm{~g} / \mathrm{mol}$. 
Table 2 Wear testing results on variable PE grades

\begin{tabular}{|c|c|c|c|c|c|c|c|c|}
\hline Sample & Date of test & $\begin{array}{l}\text { Rotation } \\
\text { speed } \\
\text { (rpm) }\end{array}$ & $\begin{array}{l}\text { Weight } \\
\text { before test } \\
\text { (g) }\end{array}$ & $\begin{array}{l}\text { Weight } \\
\text { after test } \\
\text { (g) }\end{array}$ & $\begin{array}{l}\text { Test } \\
\text { time } \\
\text { (hrs) }\end{array}$ & $\begin{array}{l}\text { Sand } \\
\text { weight } \\
\text { (kg) }\end{array}$ & $\begin{array}{l}\text { Water } \\
\text { vol. (ml) }\end{array}$ & $\begin{array}{l}\text { Wear } \\
\text { loss (\%) }\end{array}$ \\
\hline PE100 & $05 / 05 / 2017$ & 2,800 & 4.47 & 2.46 & 6 & 1.5 & 650 & 44.96 \\
\hline PE100 & $05 / 05 / 2017$ & 2,800 & 4.47 & 2.53 & 6 & 1.5 & 650 & 43.4 \\
\hline GER, UHM_1 & $26 / 01 / 2016$ & 2,800 & 4.82 & 3.46 & 6 & 1.5 & 650 & 28.21 \\
\hline GER, UHM_2 & $26 / 01 / 2016$ & 2,800 & 4.55 & 2.86 & 6 & 1.5 & 650 & 37.14 \\
\hline USA, UHM_1 & $30 / 12 / 2016$ & 2,800 & 4.46 & 2.99 & 6 & 1.5 & 650 & 32.9 \\
\hline USA, UHM_1 & $30 / 12 / 2016$ & 2,800 & 4.39 & 2.85 & 6 & 1.5 & 650 & 35 \\
\hline GER, UHM_3 & $07 / 02 / 2016$ & 2,800 & 4.31 & 3.22 & 6 & 1.5 & 650 & 25.2 \\
\hline GER, UHM_4 & $07 / 02 / 2016$ & 2,800 & 4.27 & 3.25 & 6 & 1.5 & 650 & 23.8 \\
\hline CHN, UHM_1 & $30 / 12 / 2016$ & 2,800 & 4.46 & 2.99 & 6 & 1.5 & 650 & 32.9 \\
\hline CHN, UHM_2 & $30 / 12 / 2016$ & 2,800 & 4.39 & 2.85 & 6 & 1.5 & 650 & 35 \\
\hline EnergyPro & $22 / 01 / 2016$ & 2,800 & 4.93 & 3.51 & 6 & 1.5 & 650 & 28.8 \\
\hline EnergyPro & $22 / 01 / 2016$ & 2,800 & 4.7 & 3.28 & 6 & 1.5 & 650 & 30.21 \\
\hline CHN, UHM_3 & $21 / 01 / 2016$ & 2,800 & 4.81 & 3.52 & 6 & 1.5 & 650 & 26.81 \\
\hline CHN, UHM_4 & $21 / 01 / 2016$ & 2,800 & 4.82 & 3.61 & 6 & 1.5 & 650 & 25.1 \\
\hline AUS, UHM1 & $04 / 05 / 2017$ & 2,800 & 4.93 & 3.98 & 6 & 1.5 & 650 & 19.26 \\
\hline AUS, UHM2 & $04 / 05 / 2017$ & 2,800 & 4.74 & 3.9 & 6 & 1.5 & 650 & 17.72 \\
\hline WearPro & $27 / 06 / 2016$ & 2,800 & 4.83 & 3.89 & 6 & 1.5 & 650 & 19.46 \\
\hline WearPro & $27 / 06 / 2016$ & 2,800 & 4.78 & 3.93 & 6 & 1.5 & 650 & 17.78 \\
\hline GER, UHM_5 & $26 / 06 / 2016$ & 2,800 & 5.71 & 4.67 & 6 & 1.5 & 650 & 18.2 \\
\hline GER, UHM_6 & $26 / 06 / 2016$ & 2,800 & 5.52 & 4.6 & 6 & 1.5 & 650 & 16.66 \\
\hline GER, UHM_7 & $19 / 10 / 2016$ & 2,800 & 6.28 & 5.16 & 6 & 1.5 & 650 & 17.8 \\
\hline WearPro+ & $19 / 10 / 2016$ & 2,800 & 6.49 & 5.41 & 6 & 1.5 & 650 & 15.4 \\
\hline WearPro+ & 19/10/2016 & 2,800 & 6.37 & 5.29 & 6 & 1.5 & 650 & 16.9 \\
\hline
\end{tabular}




\subsection{Third party abrasion testing}

Third party abrasion testing was organised through the Structural Testing Services arm of the University of Southern Queensland.

The testing was conducted based on SAI Global (2012) and Technische Hochschule Darmstadt (Stabik et al. 2007).

The following results were achieved after one million cycles (Table 3).

Table 3 Third party EN295 testing resulting comparing steel, HDPE and UHMWPE abrasion performance

\begin{tabular}{llllll}
\hline Sample \# & Sample description & $\begin{array}{l}\text { Average initial } \\
\text { wall thickness } \\
(\mathbf{m m})\end{array}$ & $\begin{array}{l}\text { Average wall } \\
\text { thickness after } \\
\mathbf{1 , 0 0 0 , 0 0 0} \\
\text { cycles }(\mathbf{m m})\end{array}$ & $\begin{array}{l}\text { Average } \\
\text { reduction in wall } \\
\text { thickness }(\mathbf{m m})\end{array}$ & $\begin{array}{l}\text { Reduction in } \\
\text { wall } \\
\text { thickness }\end{array}$ \\
\hline 1 & $\begin{array}{l}\text { PE100 (PN10 } \\
\text { SDR17 OD110) }\end{array}$ & 6.67 & 6.37 & 0.3 & $4.48 \%$ \\
\hline 2 & Carbon steel & 5.57 & 5.54 & 0.03 & $0.37 \%$ \\
3 & WearPro & 6.84 & 6.84 & 0.00 & 0.00 \\
\hline
\end{tabular}

The results presented in Table 3 present a few peculiarities when compared to the mortar wear index test in Section 2.1. Namely, why is PE100 performing at approximately 3:1 via the test in Section 2.1 but at an effectively infinite ratio for the test in Section 2.2?

This is likely due to the transition from impact to abrasive wear.

The mortar wear index test in Section 2.1 (originally designed for concrete testing) was conducted at a high RPM, inducing small solids to act like impact particles.

The third party abrasion testing in Section 2.2 was an iteration of the Darmstadt test, designed for vitrified clay.

Noting that the test referred to in Section 2.2 is much more specific to abrasive comparisons (and indeed is a relatively dry abrasive comparison), it stands to reason that UHMWPE should be expected to increasingly outperform PE100 or carbon steel the further the wear profile is towards abrasion as opposed to impact.

It stands to reason that a steel would outperform any plastic on impact, and that should the impact be large enough, all plastics come closer together in performance. On that basis, a designer should consider how suitable the velocity and particle size distribution of their products are when comparing performance and price. This poses the question of not 'if UHMWPE will outlast PE100 in an abrasive application', but by 'how much?' Process-specific testing to determine this outcome would need to take place.

\subsection{Non-adhesion testing - non-scaling}

Practical non-adhesion is usually a function of three aspects working in conjunction - lubrication, surface roughness, and chemical inertness. All UHMWPE products are self-lubricating naturally due to the nature and quantity of Van der Waal bonds. Subsequently, inertness and surface roughness were third party certified and tested.

\subsubsection{Third party surface roughness}

The surface roughness of UHMWPE sheets was third party tested by Shandong Institute of Metrology (SDIM) on 2 March 2010 as indicated in Figure 3.

The test result showed that the surface roughness of UHMWPE is Ra $0.16-0.22 \mu \mathrm{m}$. 

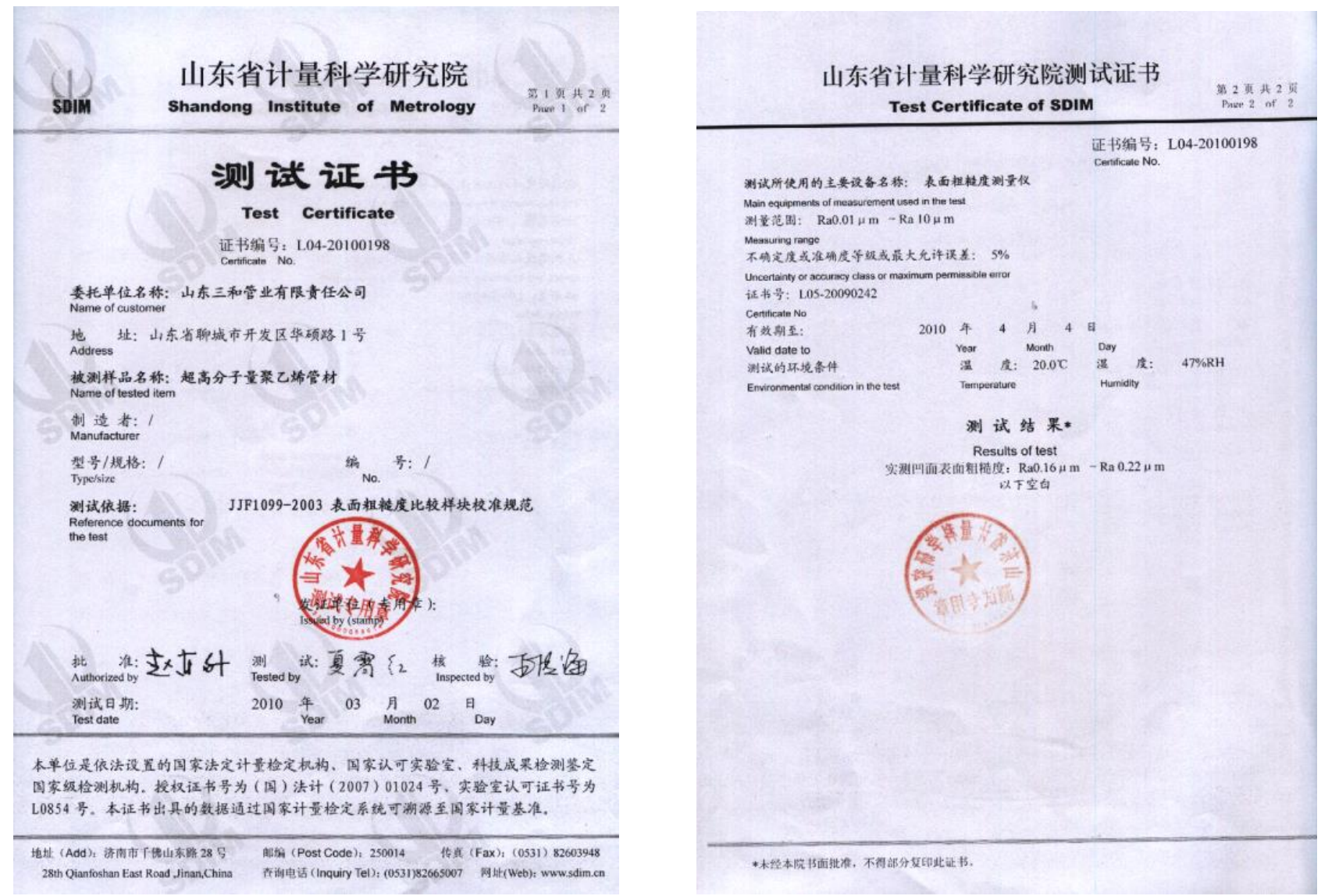

Figure 3 Surface roughness certification

Figures 4 and 5 clearly express the variation in surface between PE100 and UHMWPE when extruded correctly.

It can be seen through the gouges on both pipes that they have been dragged throughout their operation. By 'end-of-life', we are specifically saying that both pipes have blown out due to wear and are now in a laydown yard. Despite both completing their lifecycle, being dragged severely, and sitting in the sun, it is still clear which is smoother from the outside.

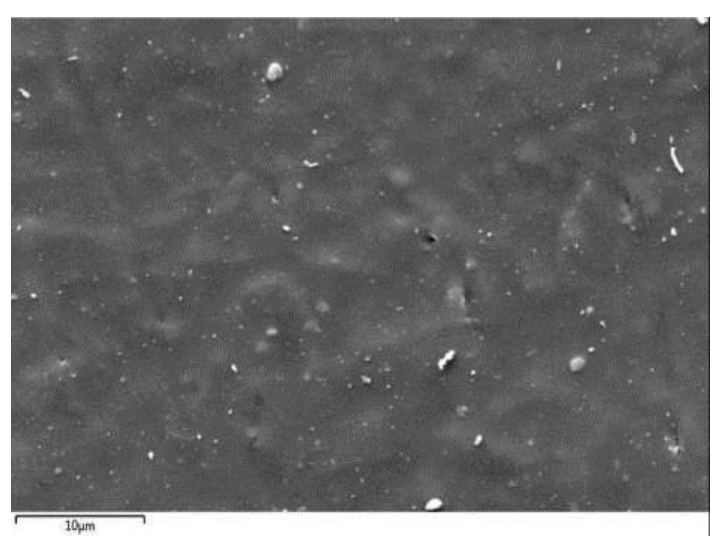

(a)

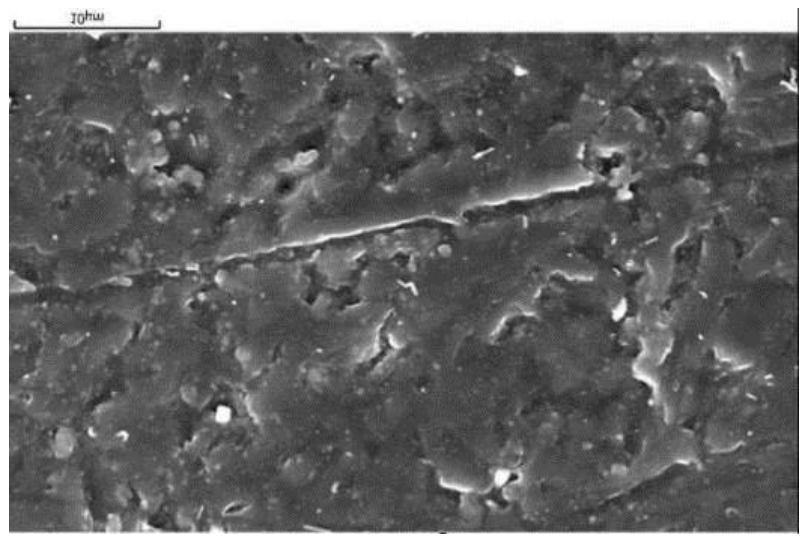

(b)

Figure 4 5,000 times magnification of (a) PE100; and, (b) EnergyPro conducted at Monash University in 2011 


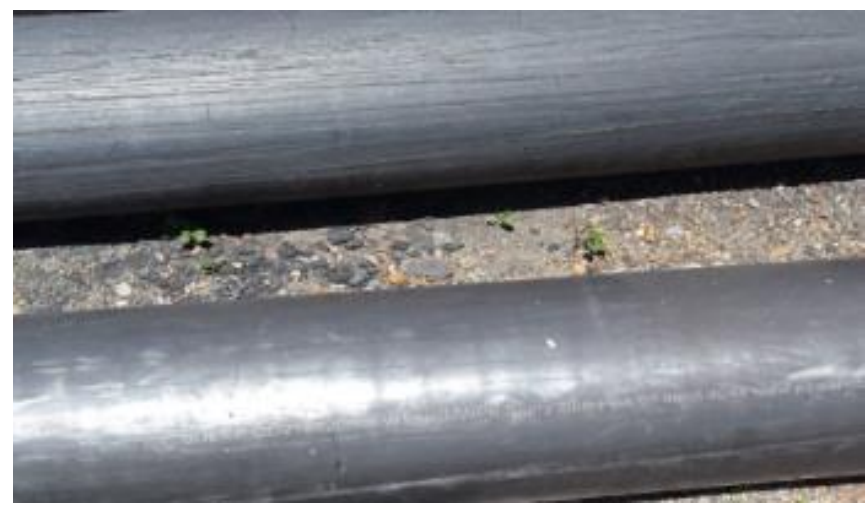

Figure 5 Gouged and worn out end-of-life pipe at a central Queensland (QLD) coal handling preparation plant. PE100 top and WearPro bottom, with clear and obvious surface roughness variations

\subsubsection{In-house surface roughness empirical data}

Theoretical values were calculated using the Darcy-Weisbach approximation for pressure loss including viscous effects.

$$
\frac{\Delta p}{L}=f_{D} \cdot \frac{\rho}{2} \cdot \frac{|v|^{2}}{D}
$$

where:

$$
\begin{aligned}
& \rho=\text { the density of the fluid }\left(\mathrm{kg} / \mathrm{m}^{3}\right) . \\
& D \quad=\text { the hydraulic diameter of the pipe }(\mathrm{m}) . \\
& v \quad=\text { the median flow velocity }(\mathrm{m} / \mathrm{s}) . \\
& f_{D} \quad=\text { the Darcy friction factor assessed on the basis of surface roughness and media (SI). }
\end{aligned}
$$

Figure 6 shows tested dynamic head data.

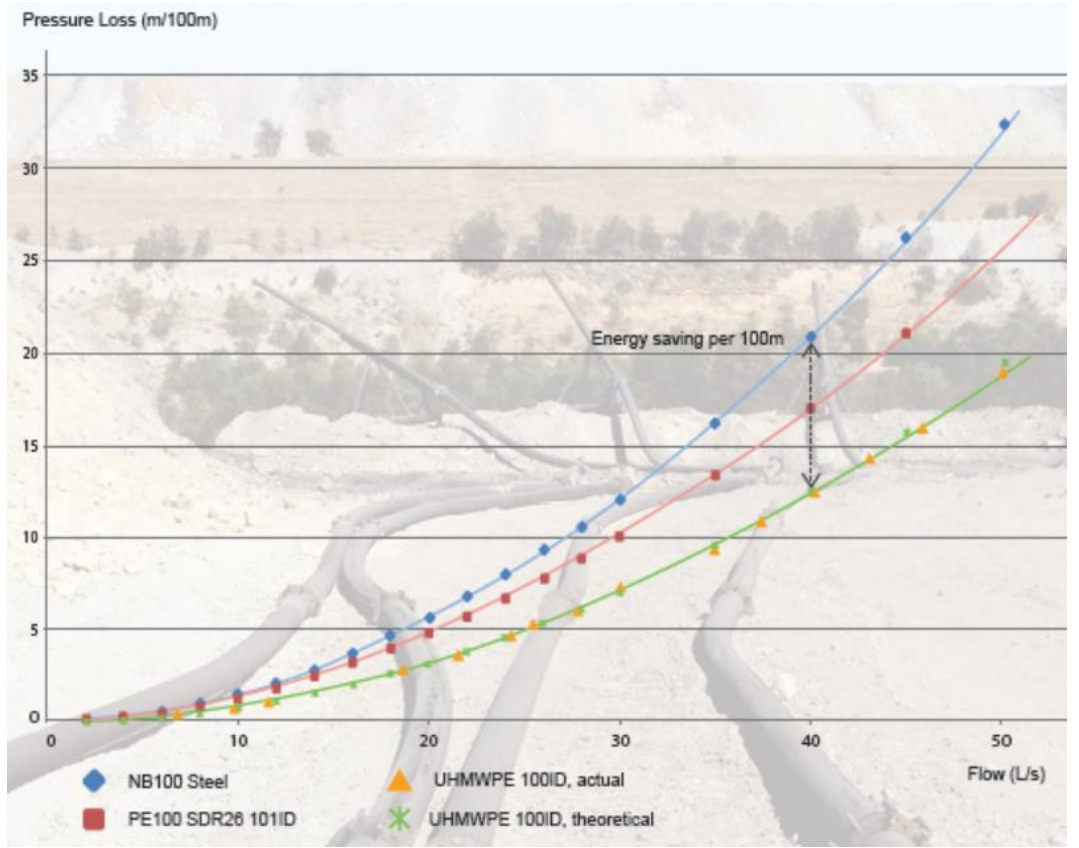

Figure 6 Pressure loss comparing empirical results against Darcy-Weisbach theoretical

Based on Figure 6, it was further confirmed that the Darcy-Weisbach approximation is a valid method for determining the pressure loss of Pipe and Buoy Pty Ltd (PBA) UHMWPE products on water. 


\subsubsection{Third party chemical inertness}

The samples were separately placed into hydrochloric acid (36\%), phosphoric acid (40\%), 93\# petrol, glacial acetic acid (40\%), and sodium hydroxide (40\%) at temperatures ranging from 20 to $80^{\circ} \mathrm{C}$ for one week. It was found that there was no surface reaction in any of these instances.

It was also attempted to paste/stick two EnergyPro plates with 502 super glue, which failed. 502 Superglue (cyanoacrylate) is advertised as being for the purpose of adhering plastics.

Collecting each of the points, EnergyPro is smoother, more chemically resistant, and self-lubricating. Considering the priorities outlined in Section 2.3 for the purposes of scaling reduction, these results in concert with each other will mean significant practical scaling benefits.

For situations where the scaling media is adhering to itself foremost rather than the pipe surface, this would still provide an advantage when cleaning (i.e. the cleaning would occur at a lower, safer, pressure).

\section{Case studies}

It would be remiss to provide testing data without any elaboration on the realities of the Australian market, and subsequent correlation with the literature review and testing data offered.

UHMWPE has wide applications as both a liner and a standalone bare product, once performance requirements are optimised for design and price.

\subsection{QLD coal handling preparation plant, central QLD, Figure 7}

- 1,600 m, 219 internal diameter stub flange table $E$, WearPro.

- Co-disposal tailings slurry, maximum solid size: $150 \mathrm{~mm}$.

- $4.2-5.2 \mathrm{~m} / \mathrm{s}$.

- 10 bar max.

Wear results - 5:1 life compared with PE100.

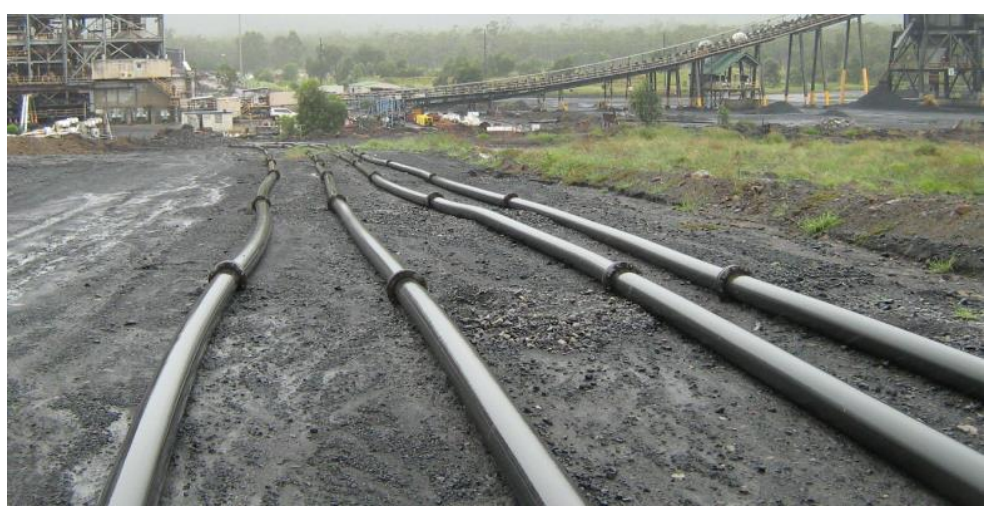

Figure 7 Burton Downs co-disposal pipelines

A heavy slurry process such as this is at the centre of our discussion regarding the testing in Sections 2.1 and 2.2. Determining maximum solid size and, subsequently, percentage of impact wear is often of critical relevance in coal co-disposal where solid sizes can often exceed $50 \mathrm{~mm}$. 


\subsection{NSW coal-fired power station, Figure 8}

- 1,600 m, 350 internal diameter by $40 \mathrm{~mm}$ wall thickness WearPro.

- Bottom ash, maximum 2.4 specific gravity.

- 10 bar operating.

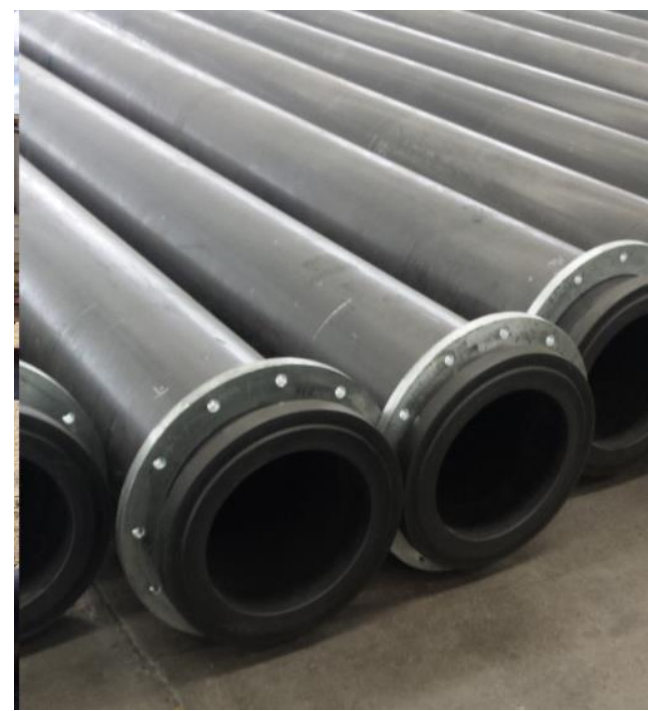

Figure 8 Liddell Power Station bottom ash pipelines

\subsection{WA, Pilbara, iron ore tailings, Figure 9}

- 3,000 m, DN400 API5LB STD steel, lined with 10 mm wall EnergyPro liner.

- Iron ore tailings.

- 50 bar running pressure.

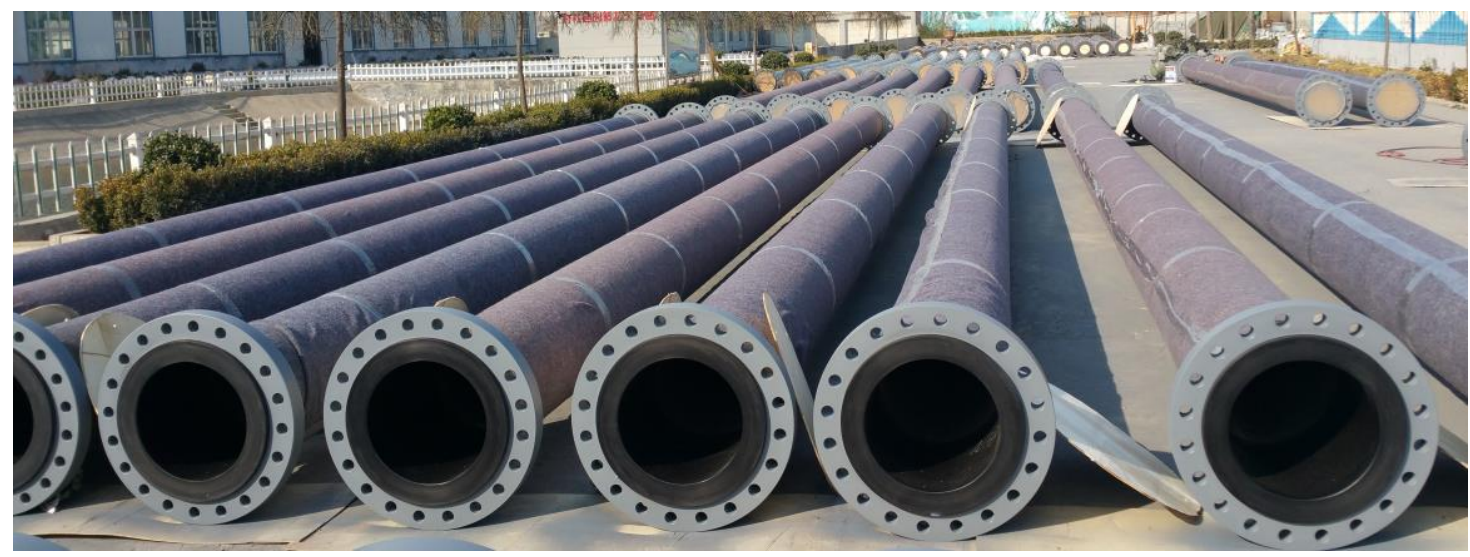

Figure 9 Iron ore tailings pipeline

In this space, wear profile is not of the highest concern. This product was actually provided on a pricing and lead-time basis. This case study shows that although bare UHMWPE is more expensive than PE100, lined steel can be competitive. It has since been shown to outperform the power consumption of the previous HDPE-lined steel pipeline by at least 30\%, according to the operator. 


\subsection{WA chemicals application}

- $1,000 \mathrm{~m}$.

- 100 NB, EnergyPro various sizes for corrosive applications.

- $\mathrm{HCl}, \mathrm{Na}_{2} \mathrm{SO}_{4}, \mathrm{NaOH}, \mathrm{SiO}_{2}, \mathrm{Ti}+$

Chemical processes like this one are at the centre of the scaling discussion. It is a very severe process that results in some scaling on all products, eventually. Specifically to this site, UHMWPE needs to be cleaned half as often as fibreglass (FRP).

Further, when cleaned, FRP requires 450 psi for scaling removal, compared with EnergyPro at 150 psi.

\section{Conclusion}

It was the objective of this paper to provide consequential data and an introduction to the potential benefits of UHMWPE piping products when compared to alternate materials whilst simultaneously comparing with direct Australian experience via case studies within which those benefits have been gleaned.

UHMWPE is the most impact and abrasion-resistant PE. However, it too has variations in performance which are largely based on molecular weight. Although unable to legally list the exact blends of each sample tested, the author can offer the proviso from our own grades and operational advantage (being the largest by volume supplier of UHMWPE piping products worldwide).

EnergyPro, WearPro and WearPro+ have clearly illustrated that longer molecular chains account for improved abrasive properties.

Subsequent to this collection of technical data, testing and cases, it is expected that engineers and users will have a firmer understanding and basis of market opportunities and practical benefits when designing paste and tailings applications.

\section{Acknowledgement}

PBA acknowledges the contribution of their technical partners in China, namely Zheng Yanhui and Sun ZhongLiang.

PBA also acknowledges the support and contribution of Celanese with regards to raw UHMWPE testing and research.

Much of the test data information and photos provided herein have been supplied in good faith by Pipe and Buoy Australia. This data and photos remain the exclusive proprietary property of Pipe and Buoy Australia.

\section{References}

ASTM International 1993, 'ASTM D256-92: Standard test methods for impact resistance of plastics and electrical insulating materials', Annual Book of ASTM Standards, vol. 8.01, ASTM International, West Conshohocken, pp. 3-5.

ASTM International 2011, Standard Specification for Ultra-High-Molecular-Weight Polyethylene Molding and Extrusion Materials, ASTM D4020-11, ASTM International, West Conshohocken, https://www.astm.org/Standards/D4020.htm

ASTM International 2012, Standard Test Method for Dilute Solution Viscosity of Ethylene Polymers, ASTM D1601-12, ASTM International, West Conshohocken, https://www.astm.org/Standards/D1601.htm

ASTM International 2015, Standard Guide for Abrasion Resistance of Mortar Surfaces Using a Rotary Platform Abraser, ASTM C1803-15, ASTM International, West Conshohocken, https://www.astm.org/Standards/C1803.htm

Braun, G \& Theyssen, J 1979, 'Ultra high molecular polyethylene - the material and its modifications', Kautschuk, Gummi, Kunststoffe, August 1979, pp. 3-3.

International Organization for Standardization 1995, Plastics - Film and Sheeting - Determination of the Coefficients of Friction, ISO 8295:1995, ISO, Geneva, https://www.iso.org/standard/20760.html

International Organization for Standardization 2001, ISO 11542-1:2001, Plastics - Ultra-high-molecular-weight Polyethylene (PE-UHMW) Moulding and Extrusion Materials - Part 1: Designation System and Basis for Specifications, ISO, Geneva, https://www.iso.org/standard/30102.html

Stein HL 1999, Engineered Material Handbook, Volume 2: Engineered Plastics, ASM International, Materials Park. 
Ticona GmbH 2007, PE-UHMW Technical Datasheet, Ticona GmbH, Frankfurt, pp. 1-3.

SAI Global 2012, EN295-3:2012, Vitrified Clay Pipe Systems for Drains and Sewers Part 3: Test Methods, SAl Global, Adelaide, https://infostore.saiglobal.com/store/details.aspx?ProductlD=1517587

Stabok, J, Makselon, M \& Tomanek, H 2007, 'Erosion resistance testing of plastic pipes', Journal of Achievements in Materials and Manufacturing Engineering, vol. 25, no. 2, http://jamme.acmsse.h2.pl/papers_vol25_2/2529.pdf 